\title{
A TECHNIQUE FOR MEASURING GROWTH RATE AND SURVIVAL OF ARMOURED SCALE INSECTS
}

\author{
M.G. HILL ${ }^{1}$, N.A. MAUCHLINE ${ }^{1}$, L.R. CATE $^{2}$ and P. G CONNOLLY ${ }^{3}$ \\ ${ }^{1}$ HortResearch, 412 No 1. Rd, Te Puke, New Zealand \\ ${ }^{2}$ HortResearch, Private Bag 3123 Hamilton, New Zealand \\ ${ }^{3}$ HortResearch, Private Bag 92 169, Auckland, New Zealand \\ Corresponding author: ghill@hortresearch.co.nz
}

\begin{abstract}
A method for measuring the size and growth rate of armoured scale insects using digital image analysis is described. It was used in a preliminary experiment that demonstrated between-plant differences in the growth rate of armoured scale insects on kiwifruit leaves. It also allowed the timing and extent of mortality factors to be measured accurately. Heavy predation of armoured scale insects on kiwifruit leaves, probably caused by earwigs, was observed for the first time. The development of this technique as a tool for both ecological studies of scale insect, and in measuring the relative resistance of kiwifruit germplasm to armoured scale insects is discussed.

Keywords: armoured scale insects, kiwifruit, predation, host plant resistance, digital imaging.
\end{abstract}

\section{INTRODUCTION}

The aim of the HortResearch kiwifruit (Actinidia spp.) breeding programme is to develop new varieties of kiwifruit with optimal fruit flavour, size and storage attributes (Cheng et al. 2004). Market access issues relating to pest and disease status are also a priority within the programme, and new varieties must be no more susceptible to pests and diseases than the existing varieties.

The two principal pest species of armoured scale insect affecting kiwifruit crops in New Zealand are greedy scale (Hemiberlesia rapax Comstock) and latania scale (H. lataniae Signoret) (Hemiptera: Diaspididae). Both species are parthenogenic and neotenous, becoming adult after only 2 moults (Rosen 1989; Steven 1990; Charles \& Henderson 2002). The sessile lifestyle of the scale insect provides an opportunity to study the development and survival of individual insects.

Studies of the susceptibility of kiwifruit germplasm to armoured scale insects began in 2002, and initial findings indicated a wide variation in the level of greedy and latania scale populations in the field on different families of kiwifruit. This finding suggested that there may be large differences in the genetically inherited susceptibility of kiwifruit germplasm to insect pests (Hill et al. 2003). As a result, the development of a simple and robust bioassay for measuring the absolute or relative susceptibility of kiwifruit germplasm to armoured scale insects was identified as a priority. This study reports on the development of a practical technique for measuring the growth rate and survival of armoured scale insects on kiwifruit.

\section{METHOD}

A flat rectangular frame was constructed to fit on the front of a digital camera, parallel to the plane of the image, and directly in front of the lens at a distance of $120 \mathrm{~mm}$. The frame consisted of a rectangular $65 \times 50 \times 0.5 \mathrm{~mm}$ piece of sheet steel, from the centre of which was cut a $45 \mathrm{~mm}$ x $30 \mathrm{~mm}$ rectangular hole. This frame was fitted securely to the front of the camera (Nikon Coolpix 995) with steel rods (2.5 $\mathrm{mm}$ diameter) fixed 
around the camera body and secured with a fixing bracket at the back. The frame could be attached and removed easily.

Scale insects on kiwifruit leaves and bark were photographed by pressing the rectangular frame flat onto the substrate with the insect(s) of choice positioned in the centre. The camera zoom was adjusted so that approximately $2-5 \mathrm{~mm}$ of the inner edge of the frame could be seen around the perimeter of the photograph. The correct exposure for the photograph was achieved by adjusting the flash and the exposure timing.

The digital images were processed using Image J imaging software (version $1.32 \mathrm{j}$; http://rsb.info.nih.gov/ij/) and a digitiser drawing tablet (Dick Smith XH1913). The image resolution (pixels per $\mathrm{mm}$ ) was calibrated by measuring the horizontal $(45 \mathrm{~mm})$ or vertical $(30 \mathrm{~mm})$ distance in the photograph between the internal borders of the frame. The area of the scale insect (measured in pixels and square millimetres) could then be accurately calculated by drawing around the edge of the wax cap of the scale insect.

The grid on a haemocytometer (a square $9 \mathrm{~mm}^{2}$ in area marked off in 0.2 and $0.25 \mathrm{~mm}$ gradations) was used to check the accuracy and possible biases in measuring areas using the frame and ImageJ. Five test areas were chosen covering more or less the full range of scale insect size: $1.75 \mathrm{~mm}^{2}, 0.8 \mathrm{~mm}^{2}, 0.4 \mathrm{~mm}^{2}, 0.08 \mathrm{~mm}^{2}$ and $0.04 \mathrm{~mm}^{2}$. Photographs of the haemocytometer grid were taken using the digital camera, with the grid positioned in the centre, bottom left-hand corner and top right-hand corner of the image. Five replicates of area estimations were taken on each of the trial areas, at three levels of magnification: $4 \mathrm{x}, 8 \mathrm{x}$ and $12 \mathrm{x}$.

The estimated area $\left(\mathrm{mm}^{2}\right)$ and the percentage error in measuring the area (expressed as $\%$ absolute deviation from the true area) were calculated for each of the five haemocytometer areas. Differences in both of these estimates were tested using analysis of variance (Minitab 14).

One-year-old rootstocks (cv. Bruno) were planted into 3-litre polythene planter bags in July 2003. One-year-old cane cuttings were chosen from eight vines from an A. chinensis parent selection trial (Cheng et al. 2004) and grafted onto the rootstocks in July 2003. The vines were chosen to represent a wide range of natural scale insect incidence under field conditions (Hill et al. 2003). On 25 October 2003, newly emerged ( $<24$ h old) greedy scale insect crawlers were brushed from laboratory cultures onto two fully expanded leaves on each of the eight vines. The leaves were examined $24 \mathrm{~h}$ later to ensure that scale insects had successfully settled. The vines were covered with fine mesh gauze netting to exclude parasitoids, and held in a shade house (50\% shade cloth) at the HortResearch Te Puke Research Centre under ambient environmental conditions.

Photographs of the scale insect caps were taken at three to four week intervals until the insects were mature. The photographs were taken of the intact scale cap, the area of which is used as a proxy for actual size of the scale insect body beneath. The same area on the leaf was photographed on each occasion, using a photographic map as a guide. This allowed the survival and growth of individual scale insects to be followed over time. Predation was measured by observing the fate of individual scale insects in sequential photographs and noting the chewing and removal of scale insect caps and bodies. Photographs were taken of scale insects primarily along the mid vein of the leaf and in the area adjacent to the petiole, as previous research has shown this area to have the highest density of insects (Steven et al. 1994). The area of each of ca 10 scale insects was measured using ImageJ on day one (while still in the crawler stage) and 34, 54, 72, 86, 109 and 122 days after inoculation. Area was plotted against age in days. The same scale insects were measured on the first four sampling occasions until day 72 after settling. On subsequent sampling occasions, scale insects from outside the original areas had to be photographed because of heavy predation of the original insects. Cap area measurements for 54- and 72-day-old scale insects were subjected to analysis of variance and Tukey's HSD test of differences between means (Minitab 14). A threeparameter logistic equation $\left(\mathrm{y}=\mathrm{a} /\left(1+\exp \left(-\left(\mathrm{x}-\mathrm{x}_{0}\right) / \mathrm{b}\right)\right)\right)$ was fitted to the data pooled for all scale insects from each of four vines using SigmaPlot 8.0. 


\section{RESULTS}

The magnification treatments had no effect upon estimated area or the \% absolute deviation from the true area for the five haemocytometer areas tested. Overall, there was a tendency to overestimate the areas (Table 1). Errors were larger when measuring the smallest areas. For instance the mean $\%$ measuring error was $12 \%$ for $0.04 \mathrm{~mm}^{2}$ and $2.8 \%$ for $1.75 \mathrm{~mm}^{2}$, while maximum measuring error for $0.04 \mathrm{~mm}^{2}$ was $50 \%$, but for $1.75 \mathrm{~mm}^{2}$ it was only $9 \%$.

The position of the area in the picture had a significant influence upon its estimated size for the larger areas $\left(0.4,0.8\right.$ and $\left.1.75 \mathrm{~mm}^{2}\right)$. Estimates of these larger areas from the bottom-left and top-right portions of the image were slightly larger than estimates from the centre of the image (Table 1), but the error was small. This positional effect was also evident in the \% measuring error for the $1.75 \mathrm{~mm}^{2}$ haemocytometer area, but not for smaller areas (Table 1).

TABLE 1: Measurements of five haemocytometer areas analysed with ImageJ.

\begin{tabular}{|c|c|c|c|c|c|c|c|c|}
\hline \multirow{3}{*}{$\begin{array}{l}\text { Area } \\
\text { being } \\
\text { estimated }\end{array}$} & \multicolumn{4}{|c|}{ Estimated Area $\left(\mathrm{mm}^{2}\right)$} & \multicolumn{4}{|c|}{$\%$ absolute error } \\
\hline & \multirow[b]{2}{*}{ Mean } & \multirow[b]{2}{*}{ SD } & \multicolumn{2}{|c|}{ P-values } & \multirow[b]{2}{*}{ Mean } & \multirow[b]{2}{*}{ Maximum } & \multicolumn{2}{|c|}{ P-values } \\
\hline & & & Position & $\begin{array}{l}\text { Magnif- } \\
\text { ication }\end{array}$ & & & Position & $\begin{array}{l}\text { Magnif- } \\
\text { ication }\end{array}$ \\
\hline 1.75 & 1.778 & 0.058 & 0.06 & NS & 2.8 & 9.2 & 0.012 & NS \\
\hline 0.8 & 0.82 & 0.028 & 0.026 & NS & 3.6 & 9.4 & NS & NS \\
\hline 0.4 & 0.41 & 0.023 & 0.015 & NS & 5.3 & 12.2 & NS & NS \\
\hline 0.08 & 0.086 & 0.007 & NS & NS & 10.2 & 26.2 & NS & NS \\
\hline 0.04 & 0.043 & 0.005 & NS & NS & 12.0 & 50.0 & NS & NS \\
\hline
\end{tabular}

There were no significant differences $(\mathrm{P}>0.05)$ in the mean area of scale insects on different vines at day 54 (data not shown), but by day 72 , there were significant differences in the mean area of scale insects (Table 2). Heavy predation from day 72 onwards had a serious effect on data collection and as a result, area measurements after this date could be reliably calculated from only 4 vines.

TABLE 2: Mean area of scale insects on eight $A$. chinensis vines from different parental crosses measured 72 days after crawler settlement. Means followed by different letters are significantly different $(\mathrm{P}<0.05$; Tukey's HSD test with $5 \%$ family error rate).

\begin{tabular}{cccc}
\hline Vine & $\mathrm{n}$ & \multicolumn{2}{c}{ Mean area $\left(\mathrm{mm}^{2}\right)$} \\
\hline 1 & 5 & 0.866 & $\mathrm{a}$ \\
2 & 10 & 0.927 & $\mathrm{ab}$ \\
3 & 10 & 1.027 & $\mathrm{ab}$ \\
4 & 10 & 1.047 & $\mathrm{ab}$ \\
5 & 10 & 1.120 & $\mathrm{~b}$ \\
6 & 10 & 1.242 & $\mathrm{~b}$ \\
7 & 10 & 1.273 & $\mathrm{~b}$ \\
8 & 10 & 1.276 & $\mathrm{~b}$ \\
\hline
\end{tabular}

The logistic curves achieved a good fit to the data from these four plants (Fig. 1), and all parameters were highly significant (Table 3 ). The scale insects developed at different rates on the vines, and attained quite different mean final sizes. The average final size of scale insects ranged from 0.88 to $1.58 \mathrm{~mm}^{2}$. 
TABLE 3: Three-parameter logistic growth equation $\left(y=a /\left(1+\exp \left(-\left(x-x_{0}\right) / b\right)\right)\right)$ fits to data in Figure 1. All parameters are significant $(\mathrm{P}<0.0001)$.

\begin{tabular}{|c|c|c|c|c|c|}
\hline & \multicolumn{3}{|c|}{ Parameter values ( \pm standard errors) } & \multirow[b]{2}{*}{ Adj. $R^{2}$} & \multirow[b]{2}{*}{$\mathrm{n}$} \\
\hline & $\mathrm{a}$ & $\mathrm{b}$ & $\mathrm{x}_{0}$ & & \\
\hline Vine 1 & $0.88(0.041)$ & $11.94(2.85)$ & $56.99(2.73)$ & 0.90 & 56 \\
\hline Vine 3 & $1.25(0.046)$ & $12.94(1.80)$ & $63.62(2.08)$ & 0.93 & 63 \\
\hline Vine 5 & $1.28(0.033)$ & $8.95(1.19)$ & $59.38(1.40)$ & 0.91 & 64 \\
\hline Vine 6 & $1.53(0.049)$ & $6.94(0.83)$ & $61.94(1.21)$ & 0.94 & 52 \\
\hline
\end{tabular}

On day $72,23 \%$ of the scale insects were predated. By day 86 , predation had risen to $73 \%$, and it reached $91 \%$ by day 109 (Fig. 1). Some of the scale insect caps and base plates were completely removed, leaving no sign of the insect. In other instances, the scale insect cap had clearly been chewed open by a mandibulate predator and the scale insect body removed. No diurnal predators (e.g. coccinellidae) were observed on the plants. The only large mandibulate insects observed around the plants were earwigs (Forficulina auricularia L.), which were observed nesting in the gauze netting covering the plants.

No parasitism was observed in the trial.

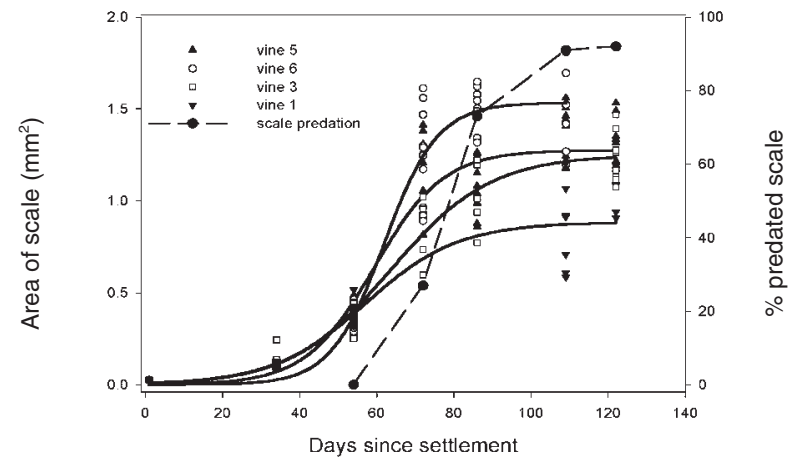

FIGURE 1: Growth of greedy scale insect on leaves from four $A$. chinensis vines of differing genotypes and 3-parameter logistic equations (solid lines) fitted to data from each vine. Dotted line denotes percentage of scale insects predated.

\section{DISCUSSION}

The photographic technique described here is an easy and effective way of measuring the growth and survival of sessile scale insects on a range of substrates. It has the potential to form the basis of a bioassay for evaluating the susceptibility of kiwifruit germplasm to armoured scale insects and for identifying the timing and cause of various mortality factors, such as predation. While there was a small and consistent bias in overestimating areas, the technique was sufficiently accurate for the purpose of measuring scale insect area and growth rate. Scale insects were photographed in the centre of the image wherever possible, to minimise errors associated with positional effects. This method is an improvement upon an earlier method used to measure citrus red scale (Aonidiella aurantii (Mask.) growth using digital imaging with a small plastic disc as a scale for calibration (Hare et al. 1990). 
This image analysis technique has been demonstrated by measuring scale insects on flat surfaces such as leaves, but it can also be used for measuring their growth on kiwifruit canes, which are more or less circular in cross section. A correction factor must be applied to the measured area of the scale insect to account for its position on the cane relative to the edge and mid point of the cane. Assuming the cane is circular, by trigonometry the correction factor is $1 / \operatorname{Cos}(A \sin (1-2 * x / d))$; where ' $x$ ' is the distance in the image from the edge of the cane to the mid point of the insect, and ' $\mathrm{d}$ ' is the diameter of the cane. The correction factor is no more than $6 \%$ for an insect within the middle third of the cane, but it rises rapidly thereafter to over $100 \%$ for an insect near the edge.

The technique can also be used to measure growth rate of scale insects on fruit. A modified circular frame, $20 \mathrm{~mm}$ in diameter, with a $5 \mathrm{~mm}$ gap around the circumference has been constructed. The gap allows the petiole to pass through, thereby enabling the photography of scale insects close to the petiole, a common settling site for these insects on kiwifruit.

Preliminary laboratory tests confining adult earwigs with greedy scale showed that they would eat the scale insect, leaving predation damage similar to that observed in the field trial. Heavy predation of young adult scale insects has never previously been recorded on kiwifruit, and earwigs have never been recorded as potential predators of scale insects in New Zealand. The observed predation has typically resulted in the removal of the whole of the insect, leaving no signs of its former presence, which may explain why it has not previously been observed in the field. The photographic technique is an ideal way of accurately measuring this type of predation. Earwigs have been recorded as major predators of the white peach scale (Pseudaulacaspis pentagona Targioni et Tozzetti) (Hanks \& Denno 1993), and they may help to regulate populations of oystershell scale and apple mussel scale in apple orchards (McLeod \& Chant 1952). In New Zealand, earwigs have been recorded as common components of arthropod communities in some apple orchards in Canterbury (Burnip et al. 2002).

\section{ACKNOWLEDGEMENTS}

We thank Kate Stannard for assistance in taking and processing some of the photographs and Mike Clearwater for information on ImageJ. Nigel Bell, John Charles and Peter Shaw provided comments on an earlier draft. The work was funded by the Foundation for Research, Science and Technology.

\section{REFERENCES}

Burnip GM, Daly JM, Hackett JK, Suckling DM 2002. European earwig phenology and effect of understorey management on popoulation estimation. New Zealand Plant Protection 55: 390-395.

Charles JG, Henderson RC 2002. Catalogue of the exotic armoured scale insects (Hemiptera: Coccoidea: Diaspididae) in New Zealand. Journal of The Royal Society of New Zealand 32: 587-615.

Cheng CH, Seal A, Boldingh H, Marsh K, MacRae EA, Murphy S, Ferguson AR 2004. Inheritance of taste characters and fruit size and number in a diploid Actinidia chinensis (kiwifruit) population. Euphytica $138: 185-195$.

Hanks LM, Denno RF 1993. Natural enemies and plant water relations influence the distribution of an armored scale insect. Ecology 74(4): 1081-1091.

Hare JD, Yu DS, Luck RF 1990. Variation in life history parameters of California red scale on different citrus cultivars. Ecology 71(4): 1451-1460.

Hill MG, Fullerton R, Manning M, Meier X, Tyson J, Mauchline N 2003. Pest and disease resistant kiwifruit - what are the prospects? Kiwifruit Journal May-June(May/June 2003): 18-20.

McLeod JH, Chant DA 1952. Notes on the parasitism and food habits of the European earwig, Forficulian auricularia L. (Dermaptera: Forficulidae). Canadian Entomologist 106: 343-345. 
Rosen D ed. 1989. Armored scale insects: their biology, natural enemies and control. Elsevier, Amsterdam, The Netherlands. 272 p.

Steven D 1990. Entomology and kiwifruit. In: Warrington IJ, Weston GC ed. Kiwifruit Science and Management. New Zealand Society for Horticultural Science, Palmerston North, New Zealand. Pp. 363-412.

Steven D, Tomkins A, Blank R, Charles JG 1994. A first-stage integrated pest management system for kiwifruit. British Crop Protection Council, Brighton, UK. Pp. 135142. 